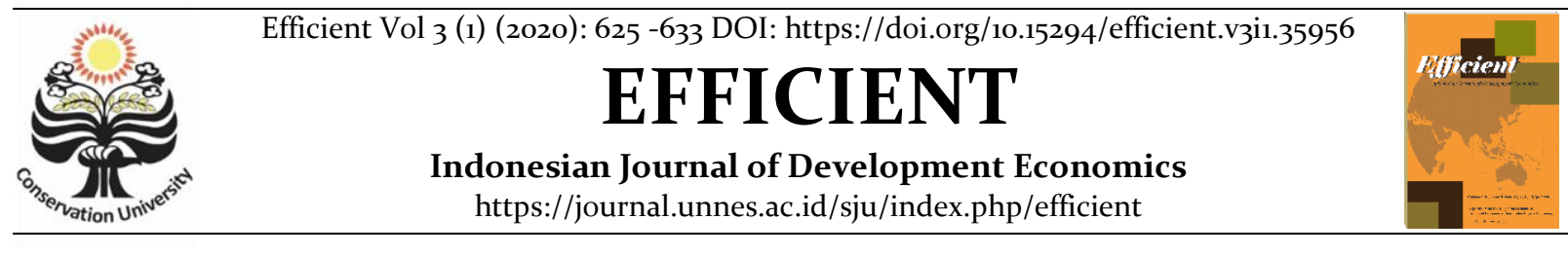

\title{
Dampak CSR terhadap Kesejahteraan Masyarakat Binaan Ternak PT. PLN Tanjung Jati B
}

\author{
Muhammad Chaniv Syarifuddin ${ }^{凶}$ \\ Jurusan Ekonomi Pembangunan, Fakultas Ekonomi, Universitas Negeri Semarang \\ Permalink/DOI: https://doi.org/10.15294/efficient.v3i1.35956
}

Received: July 2019 ; Accepted: October 2019 ; Published: January 2020

\begin{abstract}
Corporate Social Responsibility (CSR), is the company's commitment to contribute to economic development that is supported by taking into account aspects of the partnership program and community development. PT. PLN TJB as one of the large and medium-sized industrial companies that runs CSR programs, namely the planning and implementation of the CSR program. This research was conducted to see the plan to implement the partnership and Community Development program implemented by PT. PLN TJB and see the effect of the Partnership and Community Development Program on the welfare of PT. PLN TJB. This research method is quantitative descriptive using primary data with the number of respondents as many as 50 people who are members of integrated livestock fostered groups. The analytical tool used is SPSS. The results showed the implementation of Corporate Social Responsibility implemented by PT. PLN TJB Goes Well. The CSR program received a positive response from the community. The community also welcomed the CSR program of PT. PLN TJB. The relationship between the implementation of CSR programs in partnership programs involves several parties, namely the CSR unit of PT. PLN TJB, Higher Education, Local Government, and Livestock-guided Community PT. PLN. Partnership implementation program through three stages of planning, implementation and evaluation. For the Community Development program the implementation of the CSR Program, PT. PLN TJB channeled aid to the community directly, but for infrastructure and the environment PT. PLN involves the village government in carrying out its CSR activities. The role of companies in village economic development is quite central. The company has a positive influence on society. CSR programs conducted by PT. PLN TJB has been quite successful with the welfare of the communities surrounding PT. PLN TJB. Like CSR in the economic field through flashlight programs and tourist villages that provide direct to the successful with the welfare of the communities surrounding PT. PLN TJB. Like CSR in the
surrounding community. Free treatment program that gets enthusiastic from the community.
\end{abstract}

Keywords: Study, online transportation, conventional, Semarang

\begin{abstract}
Abstrak
Corporate Social Responsibility (CSR), adalah komitmen perusahaan dalam berkontribusi pada pengembangan ekonomi berkelanjutan dengan memerhatikan aspek program kemitraan dan bina lingkungan. PT. PLN TJB sebagai salah satu perusahaan industri besar dan beroperasi secara nasional memiliki permasalahan mendasar dalam penerapan CSR, yaitu perencanaan dan pelaksanaan program CSR tersebut. Penelitian ini dimaksudkan untuk melihat mekanisme pelaksanaan program kemitraan dan bina lingkungan yang dilaksanakan PT. PLN TJB serta melihat pengaruh Program kemitraan dan bina lingkungan terhadap kesejahteraan masyarakat binaan PT. PLN TJB. Metode dalam penelitian ini adalah kuantitatif diskriptif menggunakan data primer dengan jumlah responden sebanyak 50 orang yang tergabung dalam kelompok binaan ternak terpadu. Alat analisis yang digunakan adalah SPSS Hasil penelitian menunjukkan Implementasi Corporate Social Responsibility yang dilaksanakan oleh PT. PLN TJB berjalan secara baik. Adanya program CSR mendapatkan respon positif dari maraka CSR PT PLN TIB, Pe CSR PT. PLN TJB, Perguruan Tinggi, Pemerntah Daerah, serta Meranan program kemitraan melalui tiga tahapan yakni perencanaan, pelaksanaan dan infrastuktur dan lingkungan PT. PLN melibatkan pemerintah desa dalam pelaksanaan kegiatan CSR nya. Peran perusahaan dalam pembangunan ekonomi desa cukup sentral. Adanya
perusahaan memberikan dampak positif terhadap masyarakat. Program CSR yang dilakukan PT. PLN TJB cukup berpengaruh terhdap kesejahteraan masyarakat sekitar PT. PLN TJB. perusahaan memberikan dampak positif terhadap masyarakat. Program CSR yang dilakukan PT. PLN TJB cukup berpengaruh terhdap kesejahteraan masyarakat sekitar PT. PLN TJB.
Seperti CSR bidang ekonomi melalui program senter dan desa wisata yang memberikan dampak langsung ke pendapatan masyarakat sekitar. Serta program pengobatan gratis yang mendapatkan antusias dari masyarakat.
\end{abstract}

\section{Kata Kunci: Belajar, transportasi online, konvensional, Semarang}

How to Cite: Syarifuddin, M. (2020). Dampak CSR terhadap Kesejahteraan Masyarakat Binaan Ternak PT. PLN Tanjung Jati B. Efficient: Indonesian Journal of Development Economics, 3(1), $625-633$. https://doi.org/10.15294/efficient.v3i1.35956

(C) 2019 Semarang State University. All rights reserved

\footnotetext{
Alamat Korespondensi :

Alamat: Gedung L2 Lantai 2 FE Unnes

Kampus Sekaran, Gunungpati, Semarang, 50229

E-mail : muhammadchaniv114@gmail.com
}

ISSN 2655-6197 


\section{PENDAHULUAN}

Perusahaan dalam menjalankan usaha menghasilkan dampak eksternalitas, baik yang bersifat negatif maupun positif . Dampak eksternalitas negatif perusahaan, terutama yang menjalankan usaha di bidang pemanfaatan sumber daya alam juga terkait dengan semakin meningkatnya kerusakan lingkungan, mulai dari penggundulan hutan, polusi udara dan air, hingga perubahan iklim (Herlin, 2008).

Tak terkecuali pada PLTU Tanjung Jati B selaku perusahaan yang memproduksi listrik. Menurut Laporan WALHI pada 2015 PLTU menghasilkan beberapa dampak negatif bagi masyarakat dan lingkungan sekitar.

Menurut Fitri, dkk (2015) dengan adanya PLTU Tanjung Jati B Kabupaten Jepara menyebabkan berbagai eksternalitas baik negatif maupun positif. Dampak Sosial Setelah berdirinya pembangkit PLTU Tanjung jati B, khususnya masyarakat desa Tubanan betulbetul dihadapkan pada perubahan prilaku sosial yang keluar dari tradisi pedesaan selama ini. Kebutuhan dasar warga masyarakat desa Tubanan tersebar secara instant. Masyarakat desa Tubanan hampir semua mempunyai alat transportasi yang namanya sepeda motor bahkan mobil tidak lagi menjadi barang mewah. Dinamika sosial ini juga merubah pikiran, bahwa sekolah dan bekerja menjadi sama-sama pentingnya, dinamika sosial ini pun merubah prilaku warga. Sinergitas warga pendatang juga mampu mempengaruhi dinamika asli masyarakat desa Tubanan yang sebelumnya tidak kenal "kafe" akhirnya biasa waktu nya dihabiskan di kamar menjadi dihabiskan di kafe. Selain dampak social adanya PLTU Tanjung Jati B juga berdampak pada ekonomi yakni pertumbuhan ekonomi masyarakat sekitar dan terbukanya lapangan kerja. Akan tetapi banyak lapangan kerja yang tersedia adalah tenaga kerja kasar, seperti buruh bangunan dan pekerja kasar ketika sedang ada peremajaan mesin bukan tenaga kerja dengan kontrak jangka panjang akan tetapi pekerja dengan kontrak borongan.

Dalam penelitian ini juga menemukan sodetan kali yang mengaliri kurang lebih $50 \mathrm{Ha}$ sawah bersebelahan langsung kawasan pembangkit PLTU, sebelah timur tidak teraliri air secara baik (yang dibenarkan oleh para Petani pemilik sawah setempat). Dampak terhadap pertanian yang masih dirasakan secara bersama adalah kebocoran cerobong per Juni 2011, akan tetapi berkat mediasi yang dilakukan oleh pemerintah kabupaten Jepara antara Petani dan pihak PLTU tersepakati ganti rugi dan tidak ada konflik yang ditimbulkan setelah kebocoran tersebut.

Selain meningkatnya kerusakan lingkungan, keberadaan perusahaan di suatu daerah juga dapat menyebabkan eksternalitas negatif berupa ketimpangan sosial dan ekonomi antara karyawan perusahaan dengan masyarakat lokal, ataupun antara masyarakat yang memperoleh manfaat dengan masyarakat yang tidak mendapat manfaat dari keberadaan perusahaan di wilayahnya. Tanggung jawab sosial perusahaan merupakan komitmen dunia usaha untuk terus bertindak secara etis, beroperasi secara legal dan berkontribusi untuk peningkatan ekonomi, bersamaan dengan peningkatan kualitas hidup dari Eksternalitas adalah dampak yang pasti terjadi dari adanya kegiatan operasional perusahaan dan tidak mungkin dihindari perusahaan. Eksternalitas yang bersifat positif misalnya berkembangnya perekonomian di wilayah sekitar industri yang baru dibangun. 
Eksternalitas yang bersifat negatif misalnya polusi yang dihasilkan dari proses produksi di lingkungan industri seperti polusi udara dan kebisingan. Dengan adanya eksternalitas dapat menciptakan stigma negatif di masyarakat.

Selain menghasilkan eksternalitas negatif sebuah perusahaan juga menghasilkan eksternalitas positif. Berbagai progam dilakukan sebuah perusahaan guna mengurangi dampak negatif kegiatan ekonomi perusahaan seperti pembayaran pajak kepada negara, program CSR, pembangunan infrastuktur di daerah.

Pemerintah berperan membuat kebijakan untuk mengurangi dampak eksternalitas negatif perusahaan ataupun kebijakan tentang tata cara pelaksanaan tanggung jawab sosial perusahaan agar sejalan dengan penerapan prinsip-prinsip good corporate governance. Asumsi dasar dari keadaan di atas adalah bahwa, pemerintah dalam melaksanakan tugasnya benar-benar semata-mata untuk kepentingan publik. Akan tetapi berbagai studi empiris menemukan bahwa aparat pemerintah dalam mengambil tindakan tidak selalu untuk kepentingan publik, tetapi juga ada kepentingan pribadi atau kelompoknya (Utama, 2007). Kepentingan pribadi atau kelompok inilah yang menyebabkan kegagalan peran pemerintah untuk memberikan layanan publik, termasuk mengurangi dampak eksternalitas negatif perusahaan. Pada keadaan ini pelaksana tanggung jawab sosial perusahaan berperan untuk mensubstitusi kegagalan pemerintah dalam menjalankan tugasnya. Tanpa diwajibkan perusahaan yang menjalankan tanggung jawab sosial perusahaan akan berusaha mengurangi eksternalitas negatif dan meningkatkan eksternalitas positif, bahkan dengan tanggung jawab sosial perusahaan, yang tidak menghasilkan eksternalitas negatif dapat memberikan layanan publik ke masyarakat secara luas (Nursahid, 2006).

Pendekatan Stakeholder menyatakan bahwa para pihak yang terlibat perlu mengevaluasi sejauh mana perusahaan telah melaksanakan perannya sesuai keinginan stakeholders (Saidi, 2003). Kegiatan evaluasi program merupakan salah satu pilar penting yang tidak dapat diabaikan dalam penyelenggaraan program, termasuk dalam pelaksanaan program tanggung jawab sosial perusahaan. Keberhasilan atau kegagalan suatu program dapat diketahui jika kita melakukan evaluasi terhadap program tersebut (Musa, 2005). Evaluasi yang terencana akan melengkapi kekurangan program yang dievaluasi memberikan dampak bagi penguatan dan pengembangan bagi program selanjutnya. Terkait dengan pelaksanaan tanggung jawab sosial perusahaan, kegiatan evaluasi menjadi suatu hal yang penting untuk dilakukan, untuk mengukur sejauh mana keberhasilan tanggung jawab sosial perusahaan yang telah dilakukan perusahaan serta memberikan informasi yang obyektif dan seimbang kepada pihak yang terlibat (stakeholders) dalam pelaksanaan tanggung jawab sosial perusahaan (Budimanta, 2008). Program CSR perusahaan ditujukan untuk meningkatkan peran perusahaan dalam komunitas sosial masyarakat. Hal ini penting, karena sebuah entitas bisnis keberadaan sebuah perusahaan tidak dapat berdiri sendiri tanpa adanya dukungan dan suport dari masyarakat. Menurut 
Susanto (2009) perusahaan dapat dengan tetap melihat penuh kepentingan melaksanakan tanggung jawab sosialnya, dengan memfokuskan perhatiannya kepada tiga hal yakni profit, lingkungan dan masyarakat. Dalam kaitannya dengan fungsi CSR, ketiga hal tersebut merupakan satu kesatuan aktifitas perusahaan yang dapat dilakukan secara simultan sesuai dengan kondisi sosio kemasyarakatan yang berkembang. Dengan menjalankan tanggung jawab sosialnya perusahaan diharapkan tidak hanya mengejar keuntungannya saja, akan tetapi juga dapat memberikan kontribusinya yang arif dan bijaksana dalam peningkatan kesejahteraan hidup masyarakat di sekitar perusahaan. Menurut Untung (2008) kontribusi CSR dalam pembangunan ekonomi masyarakat adalah dengan melibatkan seluruh komponen masyarakat dalam kegiatan CSR perusahaan. Kemiskinan sudah menjadi musuh bersama yang harus ditanggulangi oleh semua pihak. Untuk melasakanakan hal tersebut paling tidak terdapat 3 pilar utama yang harus diperhatikan. Pertama format CSR yang sesuai dengan nilai lokal masyarakat, kedua kemampuan diri perusahaan terkait dengan kapasitas SDM dan institusi, dan ketiga adalah peraturan dan kode etik ada di dalam dunia usaha.

Berdasarkan pada integrasi ketiga pilar tersebut, masyarakat akan dapat dibangun kemampuan dan kekuatannya dalam memecahkan permasalahan yang mereka hadapi dalam pencapaian kesejahteraan hidup yang lebih baik. Di zaman modern saat ini konsep CSR mencoba menggabungkan dan berusaha untuk menjelaskan berbagai isu-isu khususnya berkaitan dengan masalah sosial, kepentingan lingkungan dan kesejahteraan, keuangan dan manfaat dari perusahaan. Etika bisnis juga telah dibawa ke dalam arena tanggung jawab sosial perusahaan Corporate Social Responsibility (CSR) adalah komitmen untuk meningkatkan kesejahteraan masyarakat melalui praktik bisnis yang memberi kontribusi dari sumber daya perusahaan (Frederick, 1960).

Namun itu bukan amal tetapi merupakan strategi bisnis inti dari sebuah organisasi. Ini adalah cara melakukan bisnis untuk memenuhi kebutuhan pasar dan para pemangku kepentingan (Chatterjee, 1976). Menurut Chris (1972) tanggung jawab sosial adalah tanggung jawab sebuah organisasi terhadap dampak dari keputusan dan kegiatannya pada masyarakat dan lingkungan, melalui perilaku yang transparan dan etis yang konsisten dengan pembangunan berkelanjutan yang berdampak terhadap kesejahteraan masyarakat sekitar perusahaan dengan tetap memperhitungkan harapan stakeholder. Menurut Defisa,S (2018) distribusi frekuensi Dampak lingkungan yang dihasilkan dari aktifitas perusahaan adalah polusi udara, polusi suara dan udara panas akibat asap dirasakan oleh masyarakat. CSR sudah memberikan mafaatnya hanya pemerataannya yang kurang merata terhadap masyarakat. Masyarakat puas terhadap CSR yang telah diberikan perusahaan.

\section{METODE}

Jenis penelitian ini adalah penelitian kuantitatif. Data yang digunakan dalam penelitian ini adalah data primer yang diperoleh dari penelitian terhadap 50 anggota kelompok binaan ring I PT. PLN Tanjung Jati B 
Kabupaten Jepara dengan teknik purposive random sampling. Sedangkan metode yang digunakan untuk mengumpulkan data adalah dengan menggunakan angket/kuesioner. Variabel X adalah Corporate Social Responsibility dengan indikator, program kemitraan dan bina lingkungan. dan variabel Y adalah kesejahteraan masyarakat yang kemudian dianalisis dengan regresi linier berganda. Dalam penelitian ini menggunakan SPSS 16.0 sebagai alat bantu untuk mengolah data.

\section{HASIL DAN PEMBAHASAN}

\section{Implementasi CSR PT. PLN Tanjung Jati B}

Pelaksanaan kegiatan CSR yang dilakukan oleh PT. PLN Tanjung Jati B Kabupaten Jepara sudah berjalan secara baik. Adanya program CSR mendapatkan respon positif dari berbagai elemen masyarakat. Masyarakat sangat berantusias dengan program CSR yang dilaksanakan oleh PT. PLN TJB sehingga menyebabkan setiap kegiatan CSR yang dilaksanakan berjalan dengan lancar. Pada saat pelaksanaan kegiatan CSR seringkali mendapat hambatan dari masyarakat desa sendiri yakni Pemahaman masyarakat akan CSR, masih banyak masyarakat yang berfikir bahwa dana CSR adalah dana yang dibagibagikan begitu saja. Padahal perusahaan berharap dana tersebut gunakan untuk program berkelanjutan dan pemberdayaan masyatakat yang mampu meningkatkan kemandirian ekonomi hal ini diungkapkan oleh bapak Grahita Muhammad selaku pelaksana kegiatan CSR PT. PLN TJB.

Mekanisme pelaksanaan CSR dibagi menjadi dua tahapan proses yang pertama Proposal masuk akan dikelompokkan menjadi tiga yaitu ring I, Ring II dan Ring III, dan dikaji apakah berhak menerima bantuan atau tidak, mekanisme ini disebut NonParticipatory Rural Appraisal, ketika proposal disetujui maka akan diberikan bantuan langsung, biasanya lebih diutamakan bantuan terhadap masyarakat binaan ternak. Yang kedua melalui mekanisme Sosial Maping, hasil yang diperoleh bisa dijadikan acuan desa atau wilayah mana yang mempunyai potensi untuk dikembangkan melalui program yang telah disusun di awal tahun, atau disebut Partisipatory Rural Appraisal. Program PRA memiliki kerjasama yang bersifat berkelanjutan. Dalam pelaksanaan program CSR unit CSR PT. PLN TJB mengacu pada Keputusan Menteri BUMN No. Kep236/MBU/2003 tentang program kemitraaan dan program bina lingkungan yang wajib dilaksanakan oleh setiap perusahaan dalam menjalankan kegiatanya.

Proses pelaksanaan program kemitraan melibatkan beberapa pihak mulai dari unit CSR PT. PLN TJB, Perguruan Tinggi, Pemerintah Daerah, serta kelompok binaan PT. PLN TJB. Pelaksanaan program kemitraan melalui proses perencanaan, pelaksanaan, serta evaluasi.

Pertama proses perencanaan kelompok binaan melakukan pengajuan proposal permohonan bantuan kepada unit CSR PT. PLN TJB. Kemudian PT.PLN TJB mempelajari dan merumuskan untuk program yang akan dibuat berdasarkan kebijakan dan peraturan pemerintah daerah. Setelah rumusan program jadi PT. PLN menggandeng perguruan tinggi untuk membuat program yang akan dijalankan. Kedua pelaksanaan PT. PLN melaksanakan program CSR dengan 
pemberian modal bergulir yakni 62 ekor kambing untuk 8 kelompok yang terdapat di tiga desa, yakni Desa Tubanan, Desa Kaliaman, dan Desa Bondo. Dalam tahap pelaksanaan PT. PLN juga bekerjasama dengan perguruan tinggi untuk memberikan pelatihan kepada kelompok binaan ternak PT. PLN TJB, seperti pembuatan pupuk organik, pembuatan organik, serta pemberian kandang komunal. Selain itu PT. PLN TJB dan Perguruan tinggi melakukan monitoring mengenai perkembangan usaha. Dalam tahap pelaksanaan program kemitraan CSR pemerintah daerah juga turut berperan melakukan pengawasan untuk memastikan kegiatan program kemitraan telah berjalan sesuai perda dan perbup yang ada. Ketiga tahap evaluasi, dalam tahap ini kelompok binaan ternak PT. PLN TJB memberikan laporan mengenai perkembangan terakhir mengenai hasil usaha kepada PT. PLN untuk dilakukan evaluasi bersama perguruan tinggi untuk melakukan riset demi kelanjutan usaha. Setelah selesai melakukan evaluasi terhadap perkembangan ekonomi kelompok binaan ternak PT. PLN memberikan laporan kepada pemda terkait mengenai perkembangan ekonomi masyarakat anggota kelompok binaan ternak PT. PLN TJB.

Masyarakat sangat antusias dengan adanya kegiatan CSR. Dalam pelaksanaan kegiatan Unit CSR PT. PLN TJB seringkali menemui kendala. Kendala yang dihadapi oleh Unit CSR PT. PLN TJB diantaranya adalah Pemahaman masyarakat akan CSR, masih banyak masyarakat yang berfikir bahwa dana CSR dalah dana yang dibagi-bagikan begitu saja. Padahal perusahaan berharap dana tersebut gunakan untuk program berkelanjutan dan pemberdayaan masyatakat yang mampu meningkatkan kemandirian ekonomi.

Kegiatan sentra ternak terpadu cukup diminati oleh masyarakat binaan, bahkan untuk kegitan SENTER sudah berjalan di tahap kedua untuk saat ini. Menurut pendapat pak Sujito selaku ketua kelompok ternak satwa makmur mengatakan bahwa pada tahap awal monitoring dalam 4 bulan setelah pelaksanaan program jumlah kambing yang dihasilkan dari bantuan 62 ekor kambing menghasilkan 76 ekor kambing atau kalau ditotal sebanyak 138 ekor. Untuk program SENTER ini salah satu program CSR sektor perekonomian yang cukup berhasil, beberapa anggota kelompok ternak menuturkan bahwa pada tahun pertama setiap anggota dapat memperoleh 2-4 ekor kambing. Akan tetapi program sentra ternak masih terkendala monitoring yang berjalan kurang lancar, bapak Karniyanto selaku ketua kelompok satwa makmur menuturkan bahwa sudah 3 bulan proses monitoring tidak terlaksana sehingga para kelompok ternak bingung untuk pelaporan hasil ternak kelompok.

\section{Uji Validitas dan Reliabilitas}

Dari hasil uji validitas dapat diketahui bahwa masing-masing item pernyataan memiliki nilai $\mathrm{r}$ hitung $>\mathrm{r}$ tabel (0.275) dan bernilai positif. Dengan demikian butir-butir pernyataan tersebut dikatakan valid. Dan dari hasil uji reliabilitas diketahui bahwa masingmasing variabel memiliki Cronbach's Alpha > o,6o yaitu o.808. Dengan demikian butir-butir pernyataan tersebut dapat dikatakan reliabel.

\section{Regresi Linear}

Hasil olahan statistik regresi linier berganda yang dibantu program SPSS 16.0 dapat dilihat pada tabel 1: 
Tabel 1. Hasil Regresi Linier Berganda

\begin{tabular}{llll}
\hline \multicolumn{1}{c}{ Variabel } & Koefisien & $\begin{array}{c}\text { T- } \\
\text { Statistk }\end{array}$ & Prob \\
\hline Konstanta & 1.595 & 1.144 & 0.258 \\
Program & 0.179 & 3.236 & 0.002 \\
kemitraan & & & \\
Bina & 1.533 & 12.790 & 0.000 \\
lingkungan & & & \\
R2 & 0.946 & & \\
Adj & 0.928 & & \\
R-Squared & & & \\
F-Statistik & 337.343 & & \\
N & 55 & & \\
\hline
\end{tabular}

Sumber: Data diolah, 2018

Berdasarkan tabel 1.2 maka persamaan regresi dapat disajikan pada persamaan berikut:

$$
\mathrm{Y}=1,595+0,179 \mathrm{X}_{1+1,533} \mathrm{X}_{2}
$$

Jika Y adalah penggunaan Kesejahteraan Masyarakat, maka hasil (Nilai konstanta dan koefisient ) regresi tersebut dapat diinterpretasikan sebagai berikut:

Nilai konstanta pada hasil regresi tersebut dapat diartikan jika semua variabel independen atau variabel bebas memiliki nilai nol (o) maka jumlah penggunaan transportasi online sebanyak 1,595 .

Nilai koefisien program kemitraan $\left(\mathrm{X}_{1}\right)$ adalah 0,179. Hal ini dapat diartikan bahwa apabila harga mengalami penambahan sebesar 1 rupiah maka kesejahteraan masyarakat naik sebesar o,179 dengan asumsi variabel lainnya tetap. Dari hasil uji tersebut dapat disimpulkan bahwa variabel program kemitraan memiliki pengaruh yang negatif dan signifikan terhadap kesejahteraan masyarakat binaan ring I PT. PLN TJB Kabupaten Jepara. Hal tersebut sesuai dengan teori pemberdayaan masyarakat bahwa pemberdayaan yang dilaksanakan melalui program kemitraan berpengaruh terhadap kesejahteraan masyarakat. Hal ini disebabkan karena program kemitraan menyasar langsung terhadap peningkatan pendapatan dan kehidupan ekonomi masyarakat sekitar.

Nilai bina lingkungan (X2) adalah o,179. Hal ini dapat diartikan setiap kenaikan bina lingkungan sebesar 1 rupiah maka kesejahteraan masyarakat meningkat sebesar o,179 dengan asumsi variabel lainnya tetap. Dari hasil uji tersebut dapat disimpulkan bahwa variabel bina lingkungan memiliki pengaruh yang positif dan signifikan terhadap kesejahteraan masyarakat binaan ring I PT. PLN TJB Kabupaten Jepara. Hal tersebut sesuai dengan teori pembanguanan. Pelaksanaan program bina lingkungan yang meliputi fasilitas sarana prasarana, pendidikan, kesehatan dapat berdampak pada kesejahteraan masyarakat karena pelaksanaan bina lingkungan dalam hal ini pembangunan jalan desa dianggap dapat memudahkan akses masyarakat dalam aktivitas keseharian, yakni aktivitas dalam pekerjaan maupun aktivitas sosial sehingga dengan mudahnya akses dalam melaksanakan kegiatan pekerjaan sehingga meningkatkan kemudahan dalam meningkatkan pendapatan masyarakat.

\section{SIMPULAN}

Berdasarkan penelitian yang dilakukan tentang analisis dampak pemberian CSR terhadap kesejahteraan masyarakat binaan ring I PT. PLN Tanjung Jati B Kabupaten Jepara maka dapat ditarik kesimpulan berikut: 
Implementasi Corporate Social Responsibility yang dilaksanakan oleh PT. PLN TJB berjalan lancar akan tetapi mengalami beberapa kendala. Adanya program CSR mendapatkan respon positif dari masyarakat. Masyarakat juga antusias menyambut program CSR PT. PLN TJB. Mekanisme pelaksanaan program CSR pada program kemitraan melibatkan beberapa pihak yakni unit CSR PT. PLN TJB, Perguruan Tinggi, Pemerintah Daerah, serta Masyarakat kelompok ternak PT. PLN. Pelaksanaan program kemitraan melalui tiga tahapan yakni perencanaan, pelaksanaan dan evaluasi. Untuk program bina lingkungan mekanisme pelaksanaan program CSR, PT. PLN TJB menyalurkan alokasi bantuan ke masyarakat langsung, tetapi untuk infrastuktur dan lingkungan PT. PLN melibatkan pemerintah desa dalam pelaksanaan kegiatan CSR nya.

Bersasarkan hasil analisis dan pengujian hipotesis (uji F) secara simultan menunjukkan bahwa variabel program kemitraan dan bina lingkungan berpengaruh signifikan terhadap kelompok binaan ring I PT. PLN TJB ditandai dengan nilai uji $\mathrm{F}$ sebesar 337.343 dengan sinifikansi o,oo lebih kecil dari taraf signifikansi yang disyaratkan sebesar 0,05. Hal tersebut berarti jika program kemitraan dan bina lingkungan secara bersama-sama mengalami kenaikan maka akan berdampak menaikkan kesejahteraan masyrakat, sebaliknya jika program kemitraan dan bina lingkungan secara bersama-sama mengalami penurunan maka akan berdampak menurunkan kesejahteraan masyarakat.

Dampak dari pelaksanaan program hanya dapat dirasakan oleh sebagian kelompok saja. Sehingga sebagian masyarakat lainnya tidak mersakana. Seharusnya program yang dilaksanakan harus memiliki keberlanjutan sehingga tidak berjalan sementara akan tetapi berkelanjutan. Sehingga semisal kelompok program kemitraan satu selesai seharusnya membentuk kelompok tahap dua dan memberikan pinjaman modal bagi kelompok selanjutnya.

Perusahaan diharapkan lebih meningkatkan bantuan program kemitraan dan bina lingkungan karena semakin tinggi program kemitraan dan bina lingkungan yang dilaksanakan maka berpengaruh terhadap peningkatan kesejahteraan masyarakat, begitupun sebalikanya semakin kecil program kemitraan dan bina lingkungan maka pengaruhnya semakin kecil terhadap kesejahteraan masyarakat. Dengan tetap memberikan pinjaman modal yang dibarengi dengan pembinaan serta pendampingan dalam berwirausaha. Walaupun demikian perusahaan harus tetap memperhatikan aspek pendidikan dan kesehatan.

\section{DAFTAR PUSTAKA}

A.B Susanto, 2009. Reputation-Driven Corporate Social Responsibility: Pendekatan Strategik Manajemen dalam CSR, Jakarta : Esensi.

Arif Budimanta,Adi Prasetijo, Bambang Rudito. 2008. Corporate Social Responsibility. Jakarta. ISCD.

Defisa, S. 2018. Analisis Persepsi Masyarakat Pada Corporate Social Responsibility Sebagai Upaya Kesejahteraan Masyarakat. Jurnal Vol 7 No 3 (2018): Economics Development Analysis Journal.

Fauzia, Herlin. 2008. Analisis Tanggung Jawab Sosial Perusahaan ( Corporate Social Responsibility) sebagai Upaya Pengembangan Nasyarakat. Skripsi. Program Studi Komunikasi dan Pengembangan Masyarakat, Fakultas Pertanian, Institur Pertanian Bogor.

Fitri, Ning., dkk. 2015. Terang Bagi Jawa Bali, Debu bagi Warga Jepara dan Paiton. Lembar Informasi dampak proyek listrik Batubara. Walhi.

Harori, M. Iqbal. 2014. Analisis Program CSR PTPN 7 Unit Usaha Beringin Terhadap Kesejahteraan 
Masyarakat. Tesis. Fakultas Ekonomi dan Bisnis.

Universitas Lampung.

Musa, Safuri. 2005. Evaluasi Program Pembelajaran dan Pemberdayaan Masyarakat. Bandung: Yayasan Pengkajian Pendidikan Non Formal.

Nursahid, F. 20o6. Tangung Jawab Sosial BUMN. Piramedia, Depok.

Saidi, Zaim. 2003. Sumbangan Sosial Perusahaan. Jakarta : PIRAC dan Ford Foundation.

Undang-undang Republik Indonesia No 25 Tahun 2007 Tentang Penanaman Modal

Undang-undang Republik Indonesia No 40 Tahun 2007 Tentang Perseroan Terbatas. 